\title{
Aspectos histológicos e histoquímicos da cloaca feminina de Columba livia (Gmelin) (Columbidae, Columbiformes)
}

\author{
Maria Eloíza de Oliveira Teles ${ }^{1}$ \\ Maria das Graças Ribeiro ${ }^{1}$ \\ Sandra Maria das Graças Maruch ${ }^{1}$ \\ Roseli Deolinda Ribeiro ${ }^{1}$
}

\begin{abstract}
Histological and histochemical aspects of female cloaca of Columba livia (Gmelin) (Columbidae, Columbiforme). The domestic dove Columba livia (Gmelin, 1789) is a species well adapted to Brazil and the study of its reproductive biology is part of a broad research project on birds. This essay describes the morphological aspects of the cloaca of female Columba livia, describing compartments lengthwise starting from the head such as the coprodeo, urodeo and proctodeo limited by mucosal folds. Each compartment of the cloaca presents its own morphological characteristics which differ one from the other in form, height and position of mucosal projections, kinds of tissues, presence and histological aspects of glands, presence of lymphonodus. The rectum opens into the coprodeo, the ureter opens into the oviduct and the cloacal sac opening into the proctodeo. Histochemical studies have shown the presence of glycoproteins in tissue cells and gland cells on the three segments of the cloaca.
\end{abstract}

KEY WORDS. Domestic dove, morphological aspects, histochemistry, cloaca

Columba livia (Gmelin, 1789) foi introduzida no Brasil no século XVI e pertence à família Columbidae, ordem Columbiformes. Ave de pequeno porte, a pomba doméstica não apresenta dimorfismo sexual aparente, possui cabeça pequena, redonda e corpo com plumagem cheia e macia. É utilizada como fonte de alimento, além de exercer importante papel no controle biológico de pragas e insetos, bem como na disseminação de sementes (SICK 1988).

A Columba livia é uma ave bem adaptada às grandes cidades e aceita pela população; o estudo de sua morfologia interna visa contribuir para a sua reprodução controlada, preservação da espécie e sua manutenção no mercado.

Como parte de um programa de pesquisa amplo sobre a biologia reprodutiva de aves brasileiras, ou aqui introduzidas, o presente trabalho descreve aspectos histológicos e histoquímicos da cloaca da pomba C. livia.

A cloaca de aves é uma cavidade comum aos sistemas digestivo, urinário e genital e apresenta estrutura complexa, constituída de três compartimentos, definidos, cranio-caudalmente, como coprodeo, urodeo e proctodeo (GETTY 1986).

O conhecimento da morfologia da cloaca de Columbiformes possibilitará o estudo comparativo entre outras espécies de aves.

1) Laboratório de Histologia Animal, Departamento de Morfologia, Instituto de Ciências Biológicas, Universidade Federal de Minas Gerais. Avenida Antônio Carlos 6627 , 31270-910 Belo Horizonte, Minas Gerais, Brasil. E-mail: eloteles@mono.icb.ufmg.br 


\section{MATERIAL E MÉTODOS}

Para o presente trabalho, foram utilizadas seis fêmeas de Columba livia, capturadas em Belo Horizonte. Os exemplares foram sacrificados por inalação de éter sulfúrico e, após dissecação e observação macro e mesoscópica do sistema genital feminino, a cloaca foi retirada e cortada transversal e longitudinalmente, para identificação de suas cavidades internas. Em seguida foram retiradas amostras de seus três segmentos, que foram submetidos a processamento histológico.

Essas amostras foram fixadas em solução de Bouin e Helly (LILliE \& FULMER 1976), incluídas em parafina ou em glicol metacrilato (CHIARINI-GARCIA 1991) e processadas conforme técnicas histológicas de rotina: colorações em hematoxilina e eosina, tricrômico de Gomori e azul de toluidina; método de Weigert (modificado por NoGUEIRA \& RIBEIRO 1980) para evidenciação de fibras elásticas e técnica de Gomori (GOMORI 1952), para fibras reticulares.

Para demonstração de componentes químicos produzidos nos diferentes compartimentos da cloaca foram utilizados os métodos do periodic acid Schiff (PAS) e alcian blue (AB) a pH 0.5 e 2.5 (LILLIE 1954).

Os resultados foram analisados, descritos e fotografados ao microscópio Leica DiaStar.

\section{RESULTADOS}

A cloaca de Columba livia apresenta-se constituída de três compartimentos, coprodeo, urodeo e proctodeo, cujas paredes são constituídas de mucosa, submucosa, muscular e adventícia, apresentando diferenças morfológicas e funcionais, dependendo do segmento observado.

O coprodeo, segmento cranial da cloaca, é o mais dilatado dos três compartimentos e apresenta, lateralmente, a abertura do reto. Caudalmente, o coprodeo limita-se com o urodeo através da prega coprourodeal (Fig. 1), de forma anular, mais desenvolvida ventralmente e cujas faces apresentam as características histológicas correspondentes a cada compartimento que contribui para a sua formação.

Histologicamente, a mucosa do coprodeo não possui vilosidades e sim pregas baixas e largas (Figs 2,3), mais desenvolvidas na região ventral. O epitélio de revestimento é simples prismático, com células caliciformes, que apresentam reação positiva ao periodic acid Schiff (PAS) (Fig. 2) e ao alcian blue (AB) em pH 2,5 e fracamente positiva ao $\mathrm{AB}$ em $\mathrm{pH} 0,5$.

$\mathrm{Na}$ lâmina própria, de tecido conjuntivo frouxo, muito vascularizado e rico em linfócitos, observam-se glândulas tubulosas mucosas, cuja secreção é positiva ao PAS e $\mathrm{AB}$ em pH 2,5. Estas glândulas são mais freqüentes na região ventral do coprodeo, onde são observados também nódulos linfóides. A camada muscular da mucosa é constituída de fibras musculares lisas, mais desenvolvidas na região ventral.

A túnica submucosa, melhor identificada na região ventral, é de tecido conjuntivo frouxo, pouco celular, rico em fibras colágenas finas (Fig. 3), delicadas fibras reticulares e escassas fibras elásticas. 

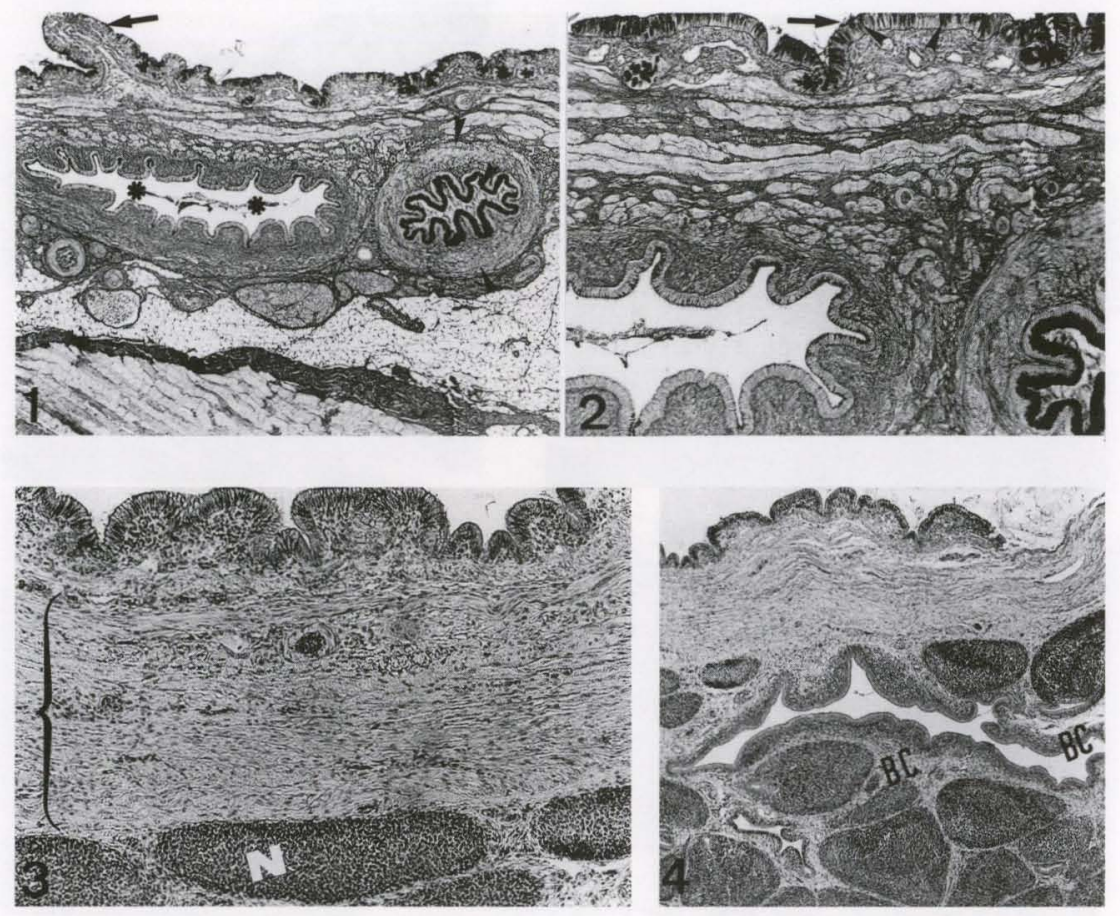

Fig. 1-4. Corte transversal do coprodeo da cloaca de Columba livia. (1) Evidenciando a prega coprourodeal (seta), oviduto $\left(^{*}\right)$ e ureter (ponta de seta), PAS; (2) mostrando aspecto histológico das pregas da mucosa (setas), com epitélio de revestimento simples prismático, contendo células caliciformes (pontas de seta), PAS; (3) região dorsal do coprodeo, mostrando o aspecto histológico das pregas da mucosa, a espessa túnica muscular (\{) e de nódulos linfóides (N), HE; (4) região dorsal do coprodeo, destacando o início da bolsa cloacal $(B C)$, HE.

A túnica muscular é espessa (Fig. 3) e apresenta fibras musculares lisas dispostas em duas camadas: circular interna e longitudinal externa, separadas por tecido conjuntivo frouxo.

Externamente à túnica muscular observam-se, na região dorsal da cloaca, feixes espessos de fibras musculares estriadas esqueléticas, cortadas transversal e longitudinalmente, além da bolsa cloacal (Fig. 4), também denominada "bursa de Fabricius" e que corresponde a um órgão linfóide presente em aves, com função imunológica de fundamental importância. É mais desenvolvida em aves jovens e estende-se do coprodeo ao proctodeo, onde se abre dorsalmente.

A túnica adventícia é constituída de tecido conjuntivo frouxo, bem vascularizado e rico em adipócitos.

O urodeo é o segundo e menor dos compartimentos da cloaca; limita-se cranialmente com o coprodeo através da prega coprourodeal (Fig. 5) e caudalmente com o proctodeo, pela prega uroproctodeal. Os ureteres se abrem na região dorsal do urodeo e o oviduto em posição mais lateral (Fig. 6). 

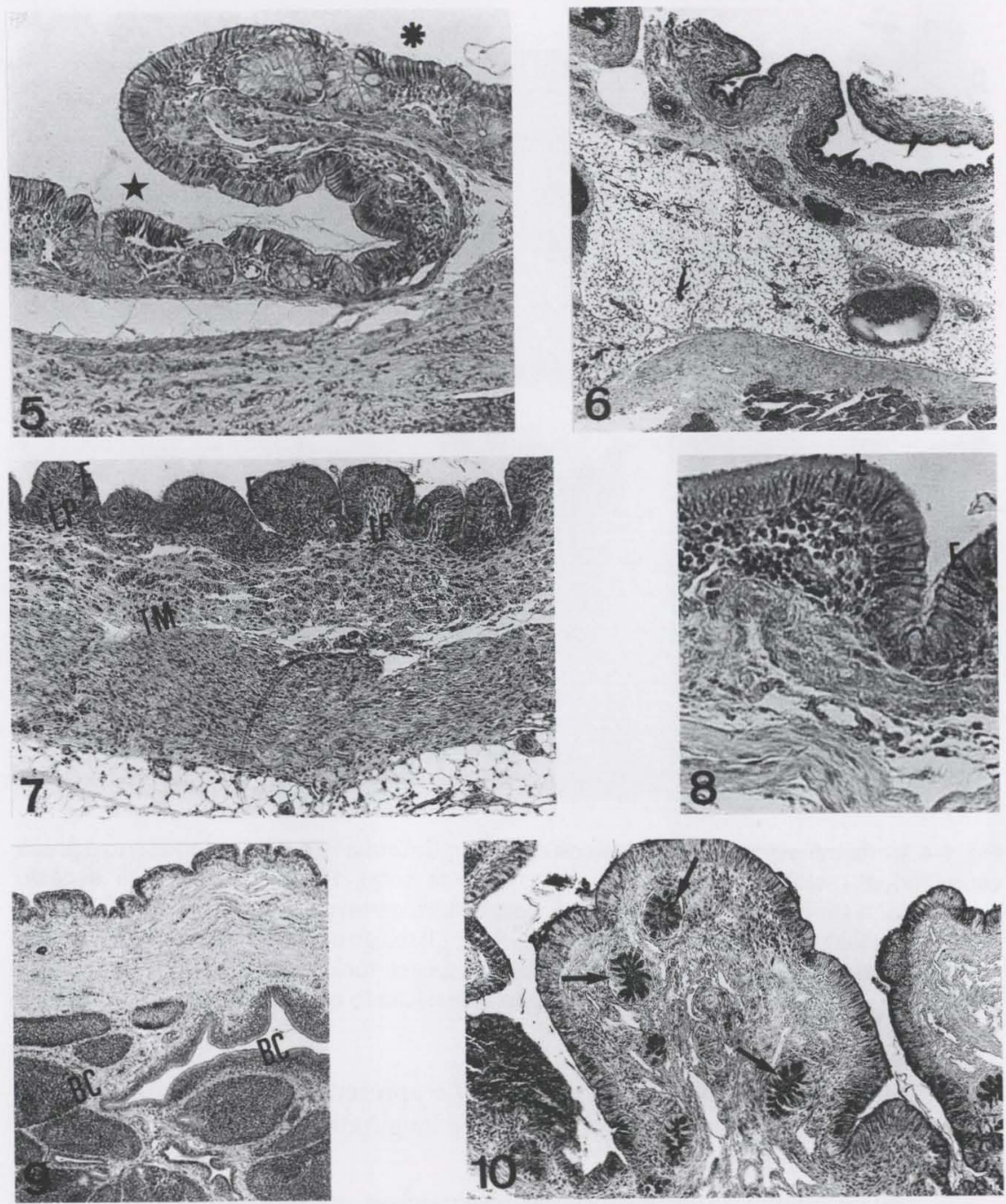

Figs 5-10. Corte transversal do urodeo da cloaca de Columba livia. (5) Evidenciando a prega coprourodeal, que separa o coprodeo $\left(^{*}\right)$ do urodeo (estrela), HE; (6) destacando o ureter $\left(^{*}\right)$ e abertura do oviduto (pontas de seta), HE; (7) mostrando o epitélio de revestimento simples prismático $(E)$, lâmina própria (LP) e túnica muscular (TM), HE; (8) mostrando o epitélio de revestimento visto em maior aumento $(E), \mathrm{HE} ;(9)$ corte transversal da bolsa cloacal, destacando nódulos linfóides (NL) e abertura da bolsa $\left(^{*}\right)$, HE; (10) destacando a presença de glândulas tubulosas mucosas (setas), PAS.

Este segundo segmento cloacal apresenta mucosa com pregas semelhantes às do coprodeo e o epitélio de revestimento é simples prismático, com poucas células caliciformes (Figs 7,8), cujas características histoquímicas são também semelhantes àquelas do coprodeo. 
Na lâmina própria, o tecido conjuntivo frouxo é bastante celular, apresenta glândulas tubulosas mucosas (Fig. 10), grande quantidade de nódulos linfóides e de linfócitos livres.

A camada muscular da mucosa e as túnicas submucosa e muscular apresentam, ventralmente, organização histológica semelhante à do coprodeo. Dorsalmente, a camada muscular da mucosa e a túnica submucosa são pouco distintas, entremeadas por fibras musculares lisas da túnica muscular. Mais externamente observa-se a bolsa cloacal, bastante desenvolvida (Fig. 9), que se inicia no coprodeo, percorre, dorsalmente, toda a extensão do urodeo, desembocando no proctodeo.

O proctodeo, segmento caudal, é o maior e mais externo dos compartimentos da cloaca, limitando-se cranialmente com o urodeo através da prega uroproctodeal e, caudalmente, com os lábios da cloaca.

Apresenta mucosa com numerosas pregas oblíquas, epitélio rico em células caliciformes e, na lâmina própria, glândulas mucosas tubulosas distribuídas em toda a sua extensão. As pregas da mucosa são mais numerosas na região dorsal, onde se observa a abertura da bolsa cloacal.

No limite com o urodeo, o epitélio de revestimento do proctodeo é pseudoestratificado prismático (Fig. 11) e à medida que se aproxima da abertura externa da cloaca, torna-se estratificado pavimentoso não queratinizado. A transição entre o epitélio que reveste internamente a cavidade proctodeal e o epitélio queratinizado que reveste os lábios da cloaca, bem como entre este e o epitélio de revestimento externo, é bem distinta (Fig. 12).

A lâmina própria do proctodeo é delicada, constituída de tecido conjuntivo frouxo bastante celular, apresentando dorsalmente, próximo à prega uroproctodeal, pequenos nódulos linfóides. Ventralmente, na base das pregas da mucosa, são observadas glândulas tubulosas mucosas, com reação histoquímica semelhante à observada nos segmentos anteriores.

A camada muscular da mucosa e a túnica submucosa são pouco distintas e histologicamente semelhantes às do urodeo.

A túnica muscular do proctodeo é delicada e mais evidente ventralmente, sendo a camada externa ligeiramente mais espessa.

$\mathrm{O}$ tecido conjuntivo adjacente à túnica muscular é rico em células adiposas, entremeadas com feixes musculares estriados esqueléticos (Fig. 13). Este tecido muscular se estende até os lábios da cloaca, onde se torna mais espesso.

Na região dorsal, próximo à bolsa cloacal, bastante desenvolvida nesta região (Fig. 14), observam-se as glândulas proctodeais, que apresentam reação PAS positiva (Fig. 15).

A face externa do proctodeo é revestida por pele fina, apresentando, na derme, folículos penáceos e terminações nervosas sensitivas (Fig. 13).

\section{DISCUSSÃO}

A fêmea da pomba doméstica Columba livia apresenta cloaca formada por compartimentos bem definidos, cujas delimitações são melhor visualizadas internamente, como tem sido descrito também em outras espécies de aves, estudadas por 
FitzGerald (1969), FEDER (1970); KomÁREK (1970, 1971) JOHNSON \& SKADHAUGE (1975); DAHM et al. (1980); KING (1981) e OLIVEIRA \& MAHECHA (1996).

De acordo com a maioria destes autores, os compartimentos cloacais são delimitados por pregas denominadas retocoprodeal (entre o reto e o coprodeo), coprourodeal (entre coprodeo e urodeo) e uroproctodeal (separando o urodeo do proctodeo). Em Columba livia, a presença de uma prega entre o reto e o coprodeo não foi observada, apenas a coprourodeal e a uroproctodeal.
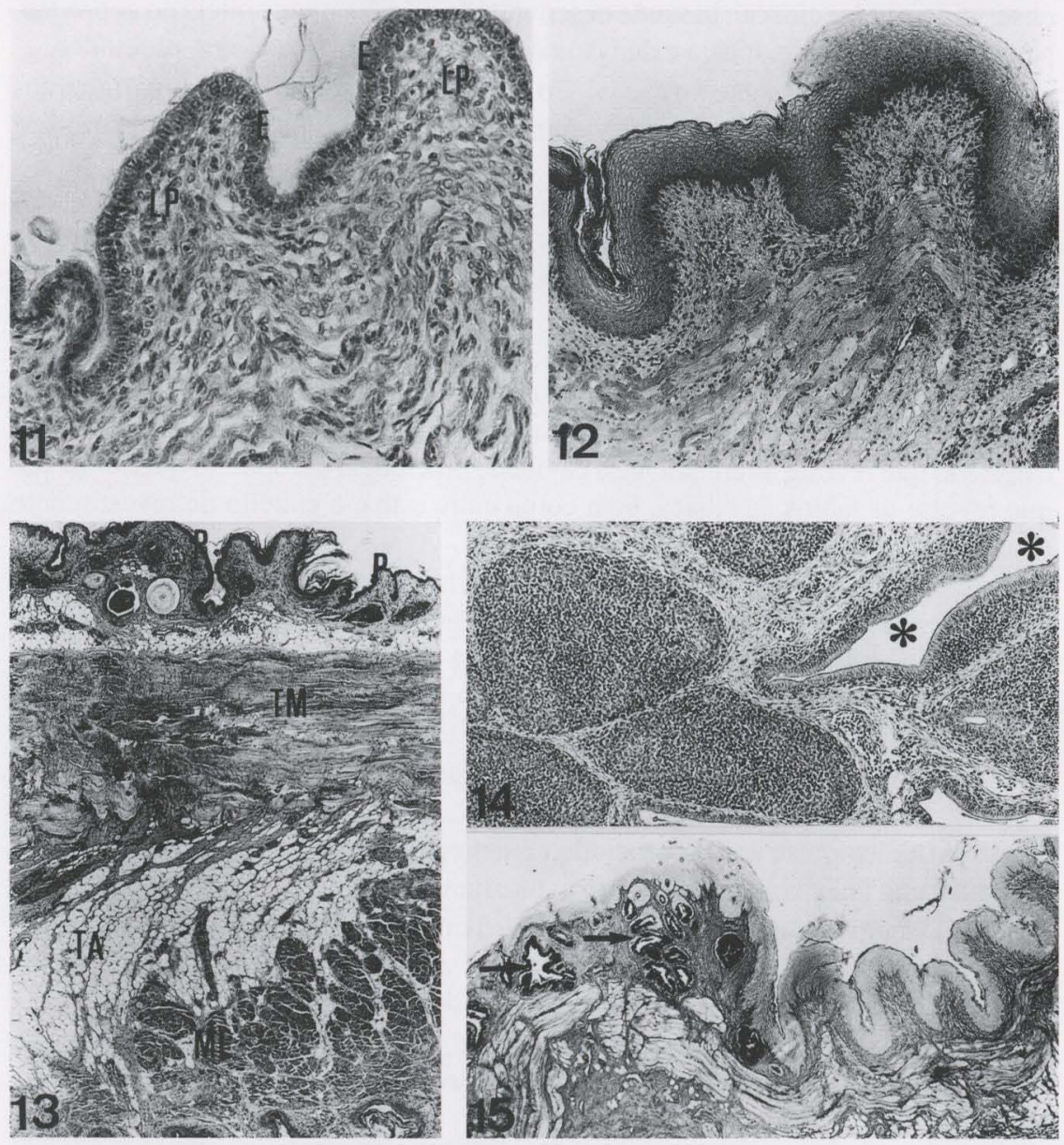

Figs 11-15. Corte transversal do proctodeo da cloaca de Columba livia. (11) Evidenciando epitélio (E) e lâmina própria (LP), HE; (12) mostrando a transição do epitélio de revestimento estratificado pavimentoso não queretinizado para queratinizado, próxima à abertura da cloaca, $\mathrm{HE}$; (13) na região do lábio da cloaca, destacando: pele fina $(\mathrm{P})$, com folículos penáceos e terminações nervosas, rica camada de tecido adiposo (TA), espessa túnica muscular (MI) e tecido muscular estriado esquelético (ME), HE; (14) mostrando a abertura da bolsa cloacal $\left(^{*}\right)$ na parede dorsal do órgão, HE; (15) destacando as glândulas proctodeais dorsais (setas), PAS. 
Para FitzGerald (1969), em codorna estas pregas são mais desenvolvidas na região dorsal, enquanto para GETTY (1986), em algumas espécies de aves a prega coprourodeal quase desaparece na região ventral.

Na espécie estudada, o reto desemboca no coprodeo, em posição lateral, e o coprodeo não corresponde a uma simples expansão do reto, conforme descrição de GETTY (1986), em outras espécies.

A mucosa do coprodeo de Columba livia apresenta características que foram também verificadas em outras aves por FEDER (1970), DAHM et al. (1980) e JOHNSON \& SKADHAUGE (1975). Algumas espécies apresentam vilosidades semelhantes às do reto, ao invés de pregas na mucosa, conforme descreveram FiTzGERALD (1969); JOHNSON \& SKADHAUGE (1975) e GETTY (1986).

$\mathrm{O}$ urodeo da pomba doméstica é o menor compartimento da cloaca e, como câmara única, ocupa uma pequena região transversal da mesma, assim como na maioria das aves estudadas. MEHROTRA (1982) observou, no entanto, que em Copsychus saularis, o urodeo é dividido em dois compartimentos: câmara urinária (anterior) e câmara genital (posterior), separadas por esfíncter.

Em Columba livia, as vias genitais e urinárias desembocam no urodeo, dorsolateralmente. No entanto, OLIVEIRA \& MAHECHA (1996) observaram que, em Nothura maculosa, o ureter desemboca no coprodeo e não no urodeo. Desse modo, o coprodeo funcionaria não só como local para recepção de fezes, mas também de urina.

De acordo com as descrições de JoHnson \& SKADHAUgE (1975) e DAHM et al. (1980), a mucosa do urodeo apresenta pregas semelhantes àquelas observadas na pomba doméstica, revestidas por epitélio simples prismático, com células caliciformes. Dentre as espécies estudadas, o epitélio descrito varia desde estratificado prismático, identificado por FEDER (1970), a pseudo-estratificado, estratificado pavimentoso e até epitélio de transição, conforme descrição de JOHNSON \& SKADHAUGE (1975). A diminuição do número de células caliciformes no epitélio e de glândulas mucosas observadas no epitélio do urodeo de Columba livia também foi descrita por KING (1981), em outras espécies de aves.

$\mathrm{Na}$ espécie descrita neste trabalho, o proctodeo apresenta-se mais longo dorsalmente e curto ventralmente, aspectos observados também em várias outras espécies de aves por KoMÁREK $(1970,1971)$. Na sua região média, o proctodeo apresenta a abertura da bolsa cloacal, estrutura que pode ser identificada desde 0 início da cloaca, na região dorsal do coprodeo. Segundo GETTY (1986), em aves imaturas a bolsa cloacal é maior do que a cloaca e tende a comprimí-la dorsalmente. De acordo com KING (1981), a "bursa" diminui gradualmente de tamanho, à medida que as aves se desenvolvem, chegando a desaparecer completamente nos adultos. Para GLICK (1960), citado por ONYEANUSI et al. (1993), a bolsa cloacal é um órgão transicional, bem desenvolvido em filhotes, e que involui completamente na maioria das aves. Em C. livia não foi feito tal acompanhamento.

A prega uroproctodeal observada tanto na região dorsal como na ventral da cloaca de C. livia foi citada também em outras espécies de aves estudadas, conforme descrição de autores como FitzGERALD (1969), DAHM et al. (1980) e KING (1979). 
Para KOMÁREK $(1970,1971)$, esta prega é mais desenvolvida dorsalmente, desaparecendo na região ventral.

Em Columba livia, a mucosa do proctodeo é revestida por epitélio que varia de pseudo-estratificado prismático na região próxima ao urodeo, a estratificado pavimentoso em sua porção terminal, fato também observado por JOHNSON \& SKADHAUGE (1975); MEHROTRA (1982) e OlIVEIRA \& MAHECHA (1996), em outras espécies. Segundo estes autores, o epitélio do proctodeo é colunar, como o do urodeo, exceto quando se aproxima da abertura cloacal, onde se torna estratificado pavimentoso. Para Hodges (1974), o epitélio do proctodeo difere daquele do urodeo, uma vez que no proctodeo as células caliciformes estão ausentes. Segundo KING (1981), tanto o urodeo quanto o proctodeo são revestidos por epitélio colunar alto e não por epitélio estratificado, e nas espécies estudadas, tais compartimentos da cloaca são locais de reabsorção de urina.

A presença de glândulas proctodeais foi descrita por KOMÁREK (1970) em anseriformes e galliformes. Na pomba doméstica, estas glândulas são tubulosas, mucosas, mais desenvolvidas na região lateral do proctodeo e nos lábios da abertura cloacal, onde a reação PAS positiva foi comprovada também em codorniz, por MCFARLAND et al. (1968). A reação PAS positiva observada nas células glandulares sugere a presença de glicoproteínas. A reação positiva ao $\mathrm{PAS}$ e $\mathrm{AB} \mathrm{em} \mathrm{pH} 2,5$ observadas nas células caliciformes e glândulas da cavidade cloacal, raramente foi descrita na literatura, o que deixa aberto o caminho para a continuidade das pesquisas, visando esclarecer, através de outras técnicas histoquímicas, a natureza química e o papel funcional das secreções das glândulas cloacais.

AGRADECIMENTOS. As autoras agradecem ao professor Ney Demas Carnevalli, pela confirmação da espécie em estudo; à bióloga do Laboratório de Histologia Animal, ICB/UFMG - Sandra Resende Lima, responsável pela preparação técnica do material estudado; ao biólogo Jorge Chehade Nasser Júnior, pela digitação do texto; à técnica do Laboratório Fotográfico, ICB/UFMG - Ivone Carmo de Oliveira, pelas ilustrações; ao tradutor Carlos Campos e à PRPq e FAPEMIG, pelo apoio financeiro.

\section{REFERÊNCIAS BIBLIOGRÁFICAS}

CHIARINI-GARCIA, H. 1991. Inclusão de material biológico em resinas plásticas. Belo Horizonte, Univ. Federal de Minas Gerais, 21p.

Dahm, H.H.; U. Schramm \& W. Lange. 1980. Scanning and transmission electron microscopie observations of the cloacal epithelia of the domestic fowl. Cell Tissue Res. 211 (1): 83-93.

FEDER, F. 1970. Die äuBeren männlichen geschlechtsorgane destruthahns (Meleagris gallopavo). Anat. Anz. 127: 347-353.

FitzGerald, C.T. 1969. The Coturnix quail anatomy and histology. Iowa, Iowa State Univ. Press, $306 \mathrm{p}$.

Getry, R. 1986. Anatomia dos animais domésticos. Rio de Janeiro, Guanabara Koogan, Vol. 2, $5^{\mathrm{a}}$ ed., 2000p.

GLICK, B. 1960. Growth of bursa of Fabricius and it relationship ho the adrenal gland in the white Pokin duck, white leghorn and outbred and in bred New Hamppshire. Poutry Science 39: 130-139.

GOMORI, G. 1952. Microscopic histochemistry principles and pratice. Chicago, Univ. Chicago Press, 480 p. 
Hodges, R.D. 1974. The histology of the fowl. London, Academic Press, 648p.

JOHNSON, O.W. \& E. SKADHAUGE. 1975. Strutural functional correlations in the kidneys and observations of colon and cloacal morphology in certain Australian birds. Jour. Anat. 120 (3): 495-505.

KinG, A.S. 1979. Systema urogenitale, p. 289-335. In: J.J. Baumel; A.S. King; A.M. LuCAS; J.E. BREAZILE \& H.E Evans. Nomina anatomica avium: an annotated anatomical dictionary of birds. New York, Academic Press, 377p.

- 1981. Cloaca, p. 63-105. In: A.S. KING \& J. MCLELLAND. 1981. Form and function in birds. London, Academic Press, 105p.

Komírek, V. 1970. The cloaca of the turkey-cock and of the cock. Acta Vet. Brno. 39: 227-234.

. 1971. The female cloaca of Anseriform e Galliform birds. Acta Vet. Brno 40: 13-22.

LILLIE, R.D. 1954. Histopathologic technic and pratical histochemstry. New York, Blakiston Co., $501 \mathrm{p}$.

LILLIE, R.D. \& H.M. FULMER. 1976. Histopathologic technic and pratical histochemstry. New York, McGraw-Hill, 942p.

MCFARLAND, L.Z.; R.L WARNER; W.O. WILSON \& F.B. MATHER. 1968. The cloacal gland complex of japanese quail. Exper. Therwil 24: 941-943.

MeHrotra, P.N. 1982. Seasonal changes in the cloaca of Cpsychus saularis (Aves, Passeres, Turdidae). Zool. Anz., Jena, 209 (2): 137-144.

NogueirA, J.C. \& R.D. Ribeiro. 1980. A simplified Weigert's method for staining elastic fibers. Arq. Esc. Vet. Univ. Minas Gerais 32: 333-335.

OliveirA, C.A. \& G.A. MAHECHA. 1996. Cloacal morphology of Nothura maculosa Temminck 1815, (Tinamidae:Tinamiforme). Anat. Anz. 178 (5): 471-476.

ONyEANusI, B.I.; C.D. EzEoKDI; J.C. ONyEANusi \& A.N. EMA. 1993. The anatomy of the cloacal bursa (Bursa de Fabricius) in the Helmeted guinea fowl (Numida meleagris galeata). Anat. Histol. Embryol. 22: 212-221.

SıCK, H. 1988. Ornitologia Brasileira. Uma Introdução. Brasília, Univ. Brasília, $3^{a}$ ed., 480p.

Recebido em 02.III.2000; aceito em 29.III.2001. 